\title{
Trend, characteristics, and pharmacotherapy of adults diagnosed with attention-deficit/hyperactivity disorder: a nationwide survey in Taiwan
}

This article was published in the following Dove Press journal:

Neuropsychiatric Disease and Treatment

I March 2017

Number of times this article has been viewed

Yu-Shian Cheng, ${ }^{1,2}$ Yu-Chiau Shyu, ${ }^{3,4}$ Sheng-Yu Lee, ${ }^{5,6}$ Shin-Sheng Yuan, ${ }^{7}$ Chun-Ju Yang, ${ }^{8}$ Kang-Chung Yang, ${ }^{8,9}$ Tung-Liang Lee, ${ }^{10}$ Liang-Jen Wang'

'Department of Child and Adolescent Psychiatry, Kaohsiung Chang Gung Memorial Hospital and Chang Gung University College of Medicine, ${ }^{2}$ Department of Psychiatry, Tsyr-Huey Mental Hospital, Kaohsiung Jen-Ai's Home, Kaohsiung, ${ }^{3}$ Community Medicine Research Center, Keelung Chang Gung Memorial Hospital, Keelung, ${ }^{4}$ Institute of Molecular Biology, Academia Sinica, Nankang, Taipei, ${ }^{5}$ Department of Psychiatry, Kaohsiung Veterans General Hospital, Kaohsiung, ${ }^{6}$ Department of Psychiatry, College of Medicine and Hospital, National Cheng Kung University, Tainan, ${ }^{7}$ Institute of Statistical Science, Academia Sinica, ${ }^{8}$ Institute of Biopharmaceutical Sciences, National Yang-Ming University, ' Genome and Systems Biology Degree Program, National Taiwan University, Taipei, Taiwan; ${ }^{10}$ Department of Radiation Oncology, University of Texas MD Anderson Cancer Center, Houston, TX, USA

Correspondence: Liang-Jen Wang Department of Child and Adolescent Psychiatry, Kaohsiung Chang Gung Memorial Hospital and Chang Gung University College of Medicine,

No I23, Ta-Pei Road, Kaohsiung City 8330I, Taiwan

Tel +88677317123 ext 8753

Fax +88677326817

Email wangliangjen@gmail.com
Objective: Attention-deficit/hyperactivity disorder (ADHD) in adults may result in functional impairment warranting clinical interventions. However, few studies have investigated the diagnosis and treatment rates of adult ADHD in non-Caucasian ethnic groups. This study used nationwide population-based data to investigate the rate of diagnosis, associated characteristics, and pharmacological treatment for adult ADHD in Taiwan.

Methods: Adults (age $\geq 18$ years) newly diagnosed with ADHD ( $\mathrm{n}=5,397)$ between January 2000 and December 2011 were enrolled from the National Health Insurance database in Taiwan. All patients were monitored until December 31, 2011. Patients who received treatment with immediate-release methylphenidate (IR-MPH), osmotic release oral system-methylphenidate (OROS-MPH), and atomoxetine (ATX) were analyzed.

Results: The cumulative prevalence of adult ADHD was $0.028 \%$, and the incidence increased 10.9-fold from 2000 to 2011 . The male to female ratio was 1.16 , and $74.9 \%$ of the patients had the inattentive type. Overall, $55 \%$ of the patients received drug therapy for ADHD, and the average treatment duration was 478.3 days. Of the total patients, $50.4 \%, 13.3 \%$, and $1.7 \%$ were prescribed with IR-MPH, OROS-MPH, and ATX, for a mean duration of 453.9, 327.7, and 161.4 days, respectively.

Conclusion: This population-based study showed an increasing trend in the diagnosis rate of adult ADHD; however, this rate is still low compared with Western countries. Approximately $45 \%$ of the adult patients with ADHD never received medication for their ADHD. Continuous efforts are needed to increase public awareness of adult ADHD.

Keywords: ADHD, gender difference, epidemiology, drug adherence, comorbidity, nonCaucasian

\section{Introduction}

Attention-deficit/hyperactivity disorder (ADHD) was thought to be solely a childhood disorder, often causing significant impairment in academic and social functions. ${ }^{1}$ However, increasing evidence suggests that $\sim 50 \%$ of children with ADHD may continue to suffer from attention problems in adulthood. ${ }^{2-4}$ Adult ADHD is often associated with various psychiatric comorbidities including mood disorders, anxiety disorders, and substance use disorders, and it has been reported to cause significant impairment in many aspects of life such as work or legal problems. ${ }^{5-11}$ The effectiveness of medication and behavioral treatment for childhood ADHD has been well established, ${ }^{12,13}$ and the treatment efficacy of psychostimulants for adult ADHD has also been supported by many studies. ${ }^{14-16}$ However, the reported rates of diagnosis and treatment of adult ADHD are low. , $6,17-22^{-12}$ 
One meta-analysis reported that the pooled prevalence of adult ADHD is $2.5 \%$ in the general population worldwide. ${ }^{23}$ Another review reported the prevalence of adult ADHD ranging from $1.2 \%$ to $7.3 \%$ in European countries. ${ }^{5}$ Some studies have investigated the prevalence of adult ADHD through faceto-face interviews. In these studies, the reported prevalence rates of adult ADHD were $4.4 \%$ in the US, ${ }^{24} 4.7 \%$ in Germany, ${ }^{9}$ and 3\% in New Zealand. ${ }^{6}$ Some studies have estimated the prevalence of ADHD using claims data. For example, one study used data from Southern California medical records, and reported that the diagnosis rate of adult ADHD ranged from $0.31 \%$ to $0.42 \%{ }^{17}$ Two other studies that also used claims data in Spain and in German reported the same diagnosis rate of adult ADHD (0.04\%) in each country. The differences in the estimated prevalence of adult ADHD between studies may be due to methodological differences and the data sources. ${ }^{6,25,26}$

Although compelling evidence indicates that adult ADHD can result in functional impairment warranting clinical interventions, ${ }^{15,16,27,28}$ adults with ADHD rarely receive treatment. Studies in European countries have reported that $<3.2 \%$ of adults with ADHD receive pharmacotherapy targeting the core symptoms of ADHD, ${ }^{21}$ although new data are available especially on pharmacoepidemiology, because when new drugs were licensed in a jurisdiction, their prescription rates increased rapidly. ${ }^{29}$ In contrast, a survey conducted in Southern California reported that $48 \%-58 \%$ of adults who were diagnosed with ADHD received pharmacotherapy for ADHD symptoms. ${ }^{17}$ This large difference may be because the data used in the US study were more recent, and differences in cultural and medical practice may have further contributed to this wide variation in treatment rate between US and European countries. Despite such low rates of diagnosis and treatment, recent evidence suggests that there is increasing recognition and treatment for adult ADHD. ${ }^{17,18,22}$ However, the rates of diagnosis and treatment for adult ADHD are still much lower compared to childhood ADHD,,$^{22,30}$ both globally and in Taiwan.

Few studies have investigated the diagnosis and treatment rates of adult ADHD in non-Caucasian ethnic groups. Moreover, the associated characteristics and comorbid psychiatric disorders with adult ADHD and the rate and patterns of pharmacological treatment for adult ADHD have rarely been reported. Understanding the characteristics of adult ADHD and patterns of medical treatment is crucial for clinical practice. Therefore, the aim of this study was to use nationwide population-based data to investigate the rate of diagnosis, associated characteristics, and pharmacological treatment for adult ADHD in Taiwan.

\section{Methods}

\section{Data source}

The protocol for this study conformed to the Helsinki Declaration and was approved by the Institutional Review Board (IRB) of Chang Gung Memorial Hospital. Patient records and information were anonymized and de-identified prior to analysis and, therefore, the need for written informed consent was waived by the IRB. The data used in this study were obtained from ambulatory claims stored in the National Health Insurance Research Database of Taiwan (NHIRD-TW). The National Health Insurance (NHI) program of Taiwan was launched in 1995 and is a mandatory universal health insurance program, with the Bureau of NHI as the sole payer of health care services. The Bureau of NHI has contracted $93 \%$ of all health care providers in Taiwan, and at least $96 \%$ of those insured have benefitted from health care services provided by a contracted hospital or clinic at least once since 1995. These medical care institutions are required to electronically submit monthly medical expense-related claims documents, including the patients' demographic data, the medical institution visited, diagnostic codes, dates of any prescriptions, drugs prescribed, and all claimed medical expenses. The database of this program contains registration files and original claim data for reimbursement. Large computerized databases derived from this system are maintained by the National Health Research Institutes, Taiwan, and are provided as NHIRD-TW to scientists in Taiwan for research purposes. The NHIRD-TW has previously been validated to be an effective resource for population-based research. ${ }^{31}$

\section{Definition of ADHD, and the incidence and cumulative prevalence rates}

This study recruited all adults (age $\geq 18$ years) who were diagnosed with ADHD from January 2000 to December 2011 and who had records available in the NHIRD-TW. In order to reduce possible misdiagnoses, ADHD was defined as at least two NHI claims records with the International Classification of Diseases, 9th revision, Clinical Modification (ICD-9-CM) code 314.X. The index date was established as the date when ADHD was first diagnosed, and medical records of these patients in the NHIRD-TW were monitored until December 31, 2011. If the identified case received another claim record with ADHD diagnosis, it was defined as an incident case. Therefore, one can only be an incident case once in the study population. As such, the study sample consisted of 5,397 adults with ADHD. ADHD subtypes included the inattentive type (ICD-9-CM code 314.00) and the predominantly hyperactive/impulsive or combined type (ICD-9-CM code 314.01, ADHD H/C type). 


\section{Definition of comorbidities and hospital level}

The following psychiatric disorders that are commonly comorbid with ADHD were identified in this study: tic disorders (ICD-9-CM code 307.2X), intellectual disability (ICD-9-CM codes 317-319), anxiety disorders (ICD-9-CM code 300.X), and depressive disorders (ICD-9-CM codes 296.2, 296.3, 300.4, or 311). The institutions where the patients were first diagnosed with ADHD were divided into two levels: hospitals and local medical clinics.

\section{Definition of ADHD medication}

ADHD medications were identified according to the Anatomical Therapeutic Chemical Classification System. According to the Food and Drug Administration of Taiwan, only three drugs were licensed to treat ADHD prior to 2011: immediate-release methylphenidate (IR-MPH), osmotic release oral system-methylphenidate (OROS-MPH), and atomoxetine (ATX). IR-MPH entered the market in Taiwan on March 1, 1995; OROS-MPH on September 1, 2004; and ATX on May 1, 2007. All prescriptions for IR-MPH, OROS-MPH, and ATX were recorded in ambulatory care, pharmacy, or hospital care claims.

Patients who received ADHD medications were defined as those with at least one record of pharmacotherapy (IRMPH, OROS-MPH, or ATX). Incidence of ADHD drug therapy was defined as the first prescription for one of these drugs. Discontinuation of ADHD medication was defined as stopping the drug for 180 days or longer. The duration of treatment was defined as the interval between the index date and the date of discontinuation or December 31, 2011. Treatment lengths were stratified into four groups: $<30$ days, 31-180 days, 181-365 days, and $>365$ days. Drug adherence was defined using the medication possession ratio (MPR), which represents the ratio of the total number of defined daily doses the patients received to the total number of days of follow-up. ${ }^{32,33}$ If the calculated MPR for a patient was $>100 \%$, the MPR was considered $100 \%$.

\section{Statistical analysis}

Statistical Package for the Social Sciences (SPSS) software version 20.0 (SPSS Inc., Chicago, IL, USA) was used for all statistical analyses. Variables were expressed as either the mean (standard deviation) or frequency. A two-tailed $P$-value $<0.05$ was considered to indicate statistical significance.

Incident cases of adult ADHD were determined annually from the first NHI claims record of newly diagnosed ADHD within the specific year (from 2000 to 2011). To determine the annual incidence of adult ADHD (per 100,000 people), the annual number of incident cases each year was divided by the total number of adults (age $\geq 18$ years) nationwide during each year. Data on the general population in Taiwan were obtained from the Directorate-General of Budget Accounting and Statistics, Executive Yuan, Taiwan. ${ }^{34}$ The cumulative prevalence rates of adult ADHD were also calculated among the total population (per 100,000) by dividing the number of cumulative cases with adult ADHD by the number of adults (age $\geq 18$ years) nationwide each year.

The proportion of patients who received medication treatment in a specific year was also calculated. Then, the cases were stratified into three age groups (18-30 years, $31-45$ years, and $>45$ years). Sex distribution and duration of medication treatment among the different age groups were compared using the chi-square test. Curve estimation linear models were used to evaluate trends with regard to the annual number of cases of ADHD, and incidence and cumulative prevalence rates, and proportions of age groups and those receiving medication treatment. Using curve estimation of linear models, the degree of freedom for regression coefficient was 1 and the total degrees of freedom for each model was 11. In addition, a multivariate logistic regression model was used to estimate the potential factors associated with medical treatment, adjusted for the year of ADHD diagnosis. The adjusted odds ratios (aORs) and $95 \%$ confidence intervals (CIs) were also calculated.

\section{Results \\ Trend of adult ADHD diagnosis}

Table 1 shows the distribution of adult patients who were newly diagnosed with ADHD during 2000-2011 in Taiwan. The annual number of new cases of adult ADHD increased from 67 in 2000 to 834 in 2011 (12.4-fold increase, $t=8.06$, $P<0.001)$, the incidence increased from 0.41 per 100,000 in 2000 to 4.45 per 100,000 in 2011 (10.9-fold increase, $t=7.35, P<0.001)$, and the cumulative prevalence increased from 0.41 per 100,000 in 2000 to 28.78 per 100,000 in 2011 (70.2-fold increase, $t=13.29, P<0.001$ ). The proportion of the three age groups (18-30 years, $31-45$ years, and $>45$ years) did not significantly change during 2000-2011. In addition, the proportion of patients receiving medication treatment did not significantly change over time $(P=0.766)$.

\section{Characteristics of the adults with ADHD}

A total of 5,397 adults with ADHD (mean age: $31.5 \pm 11.2$ years) was enrolled in this study (Table 2). Of these patients, $2,502(46.4 \%)$ were female and 2,895 (53.6\%) were male. 
Table I Distribution of adult patients who were newly diagnosed with ADHD from 2000 to 20 I I in Taiwan

\begin{tabular}{|c|c|c|c|c|c|c|c|c|}
\hline Year & $\begin{array}{l}\text { Total } \\
\text { population }^{a}\end{array}$ & $\begin{array}{l}\text { Patients } \\
\text { with ADHD }\end{array}$ & $\begin{array}{l}\text { Incidence } \\
\text { rate }^{\mathrm{b}}\end{array}$ & $\begin{array}{l}\text { Cumulative } \\
\text { prevalence }^{\text {b }}\end{array}$ & $\begin{array}{l}\text { Proportion of } \\
18-30 \text { years (\%) }\end{array}$ & $\begin{array}{l}\text { Proportion of } \\
3 \mathrm{I}-45 \text { years (\%) }\end{array}$ & $\begin{array}{l}\text { Proportion of } \\
>45 \text { years (\%) }\end{array}$ & $\begin{array}{l}\text { Proportion of drug } \\
\text { treatment (\%) }\end{array}$ \\
\hline 2000 & $16,497,603$ & 67 & $0.4 I$ & $0.4 I$ & 74.6 & 19.4 & 6.0 & 59.7 \\
\hline 2001 & $16,743,047$ & 74 & 0.44 & 0.84 & 59.5 & 28.4 & 12.2 & 63.5 \\
\hline 2002 & $16,976,243$ & 100 & 0.59 & 1.42 & 72.0 & 23.0 & 5.0 & 72.0 \\
\hline 2003 & $17,174,600$ & 99 & 0.58 & 1.98 & 66.7 & 30.3 & 3.0 & 71.7 \\
\hline 2004 & $17,344,075$ & 300 & 1.73 & 3.69 & 50.0 & 40.0 & 10.0 & 55.0 \\
\hline 2005 & $17,527,455$ & 587 & 3.35 & 7.00 & 37.0 & 49.6 & 13.5 & 33.9 \\
\hline 2006 & $17,874,404$ & 655 & 3.66 & 10.53 & 36.3 & 50.7 & 13.0 & 39.1 \\
\hline 2007 & $|7,85|, \mid 79$ & 712 & 3.99 & 14.53 & 44.8 & 44.0 & 11.2 & 50.8 \\
\hline 2008 & $18,168,727$ & 567 & 3.12 & 17.40 & 58.4 & 30.9 & 10.8 & 72.0 \\
\hline 2009 & $|8,374,6| 3$ & 630 & 3.43 & 20.63 & 59.4 & 30.5 & 10.2 & 70.2 \\
\hline 2010 & $18,566,356$ & 772 & 4.16 & 24.58 & 60.9 & 29.3 & 9.8 & 58.5 \\
\hline 2011 & $18,755,562$ & 834 & 4.45 & 28.78 & 58.9 & 30.7 & 10.4 & 56.7 \\
\hline Statistic & $t=44.11$ & $t=8.06$ & $t=7.35$ & $t=13.29$ & $t=-1.04$ & $t=0.83$ & $t=1.4 \mid$ & $t=-0.31$ \\
\hline value & $P<0.001$ & $P<0.001$ & $P<0.001$ & $P<0.001$ & $P=0.324$ & $P=0.425$ & $P=0.188$ & $P=0.766$ \\
\hline
\end{tabular}

Notes: ${ }^{\text {aAge }} \geq 18$ years. ${ }^{\text {bPer } 100,000 \text { people. }}$

Abbreviation: ADHD, attention-deficit/hyperactivity disorder.

Overall, 4,042 (74.9\%) had inattentive type ADHD and 1,355 (25.1\%) had ADHD H/C type. With regard to psychiatric comorbidities, 76 (1.4\%) patients had tic disorders, 396 (7.3\%) patients had intellectual disabilities, 3,541 (65.6\%) had anxiety disorders, and 2,670 (49.5\%) had depressive disorders. Overall, 3,983 (73.8\%) patients were first diagnosed with ADHD by doctors in hospitals and 1,414 (26.2\%) by local medical clinics. Figure 1 displays the sex distribution among the three age groups. It was found that patients aged between 18 and 30 years were mostly male $(65.1 \%)$, whereas patients older than 30 years were mostly female $(54.7 \%-60.1 \%)$.

\section{Medication treatment for adult ADHD}

Of all patients (Table 2), 2,897 (55.3\%) received at least one dose of ADHD medication (IR-MPH, OROS-MPH, or ATX) for a mean duration of 478.3 days and showed a mean MPR of $69.3 \%$. Of these patients, $2,720(50.4 \%), 719$ (13.3\%), and $92(1.7 \%)$ were prescribed with IR-MPH, OROS-MPH, and ATX, for a mean duration 453.9, 327.7, and 161.4 days, with a mean MPR of $69.5 \%, 73.4 \%$, and $85.3 \%$, respectively.

The distribution of treatment duration among age groups is shown in Figure 2. Overall, in ADHD patients with drug treatment, the proportions of patients who received medication treatment for $<30,31-180,181-365$, and $>365$ days were $21.8 \%, 32.5 \%, 11.7 \%$, and $34 \%$, respectively. A significant difference in the lengths of medication treatment was observed among age groups $(P=0.032)$. Patients aged between 18 and 30 years had the highest proportion of receiving treatment $<30$ days (23.3\%), and lowest proportion of receiving treatment $>365$ days (32\%).

Table 3 demonstrates the factors associated with pharmacotherapy for adult ADHD. Older age at the diagnosis of ADHD (relative to 18-30 years) was associated with a decreased likelihood of being prescribed with medication (31-45 years: $\mathrm{aOR}=0.40,95 \%$ CI: $0.35-0.46 ;>45$ years: $\mathrm{aOR}=0.30,95 \% \mathrm{CI}: 0.26-0.36$ ). In addition, being male (aOR $=1.79,95 \%$ CI: 1.59-2.02), having the ADHD H/C type $(\mathrm{aOR}=1.23,95 \% \mathrm{CI}: 1.07-1.41)$, comorbid anxiety disorder ( $\mathrm{aOR}=1.64,95 \% \mathrm{CI}: 1.42-1.89$ ), or depressive disorder (aOR $=1.74,95 \%$ CI: $1.52-1.99$ ) were associated with a higher probability of being prescribed with medication. However, having intellectual disability $(\mathrm{aOR}=0.54,95 \% \mathrm{CI}$ : $0.44-0.68$ ) was associated with a lower probability of being prescribed with medication.

\section{Discussion \\ Diagnosis rate of ADHD}

Based on the data from NHIRD, the cumulative prevalence of adult ADHD was only $0.028 \%$ in Taiwan throughout the study period, which is much lower than that reported in previous studies using face-to-face interviews (1.2\%-7.3\% in the general population), ${ }^{5,6,9,23,24}$ and also lower than that determined by claims data in European and US studies $(0.04 \%-0.42 \%) .{ }^{17,19,20}$ To date, no study has investigated the prevalence rate of adult ADHD in Taiwan through random sampling or face-to-face interviews using a structured diagnostic tool. Therefore, it remains unclear how many adults actually meet the diagnostic criteria of ADHD in Taiwan. Nevertheless, epidemiological studies have reported that the prevalence of ADHD in school-aged children worldwide is between $5.3 \%$ and $7.2 \%,{ }^{35,36}$ a rate similar to that reported in Taiwan (3.3\%-7.5\%). ${ }^{37,38}$ In the natural course of ADHD, the symptoms decrease in around $50 \%$ of patients at puberty or in early adulthood. ${ }^{39}$ Moreover, similar with UK, ${ }^{40}$ all 
Table 2 Characteristics of adults newly diagnosed with ADHD $(\mathrm{N}=5,397)$ from 2000 to $20 \mathrm{II}$ in Taiwan

\begin{tabular}{|c|c|c|}
\hline Characteristics & Mean or $\mathbf{N}$ & SD or $\%$ \\
\hline \multicolumn{3}{|l|}{ Age at diagnosis } \\
\hline Mean \pm SD (years) & 31.5 & 11.2 \\
\hline $18-30$ years $(n, \%)$ & 2,822 & 52.3 \\
\hline $31-45$ years $(n, \%)$ & 1,992 & 36.9 \\
\hline$>45$ years $(n, \%)$ & 583 & 10.8 \\
\hline \multicolumn{3}{|l|}{$\operatorname{Sex}(n, \%)$} \\
\hline Female & 2,502 & 46.4 \\
\hline Male & 2,895 & 53.6 \\
\hline \multicolumn{3}{|l|}{ ADHD subtypes $(n, \%)$} \\
\hline Inattentive type & 4,042 & 74.9 \\
\hline Hyperactive/impulsive or combined type & 1,355 & 25.1 \\
\hline \multicolumn{3}{|l|}{ Psychiatric comorbidity $(\mathrm{n}, \%)$} \\
\hline Tic disorders & 76 & $\mathrm{I} .4$ \\
\hline Intellectual disability & 396 & 7.3 \\
\hline Anxiety disorders & $3,54 I$ & 65.6 \\
\hline Depressive disorders & 2,670 & 49.5 \\
\hline \multicolumn{3}{|l|}{ Hospital level of first diagnosis (n, \%) } \\
\hline Medical center or regional hospitals & 3,983 & 73.8 \\
\hline Local medical clinics & $\mathrm{I}, 4 \mid 4$ & 26.2 \\
\hline \multicolumn{3}{|l|}{ Pharmacotherapy for ADHD } \\
\hline Any prescription (n, \%) & 2,987 & 55.3 \\
\hline $\begin{array}{l}\text { Duration of any drug treatment (days, } \\
\text { mean } \pm S D \text { ) }\end{array}$ & 478.3 & 733.1 \\
\hline MPR of drug treatment $(\%$, mean $\pm S D)$ & 69.3 & 32.9 \\
\hline IR-MPH prescription (n, \%) & 2,720 & 50.4 \\
\hline $\begin{array}{l}\text { Duration of IR-MPH treatment (days, } \\
\text { mean } \pm S D \text { ) }\end{array}$ & 453.9 & 728.9 \\
\hline MPR of IR-MPH treatment $(\%$, mean \pm SD) & 69.5 & 33.4 \\
\hline OROS-MPH prescription $(n, \%)$ & 719 & 13.3 \\
\hline $\begin{array}{l}\text { Duration of OROS-MPH treatment (days, } \\
\text { mean } \pm S D \text { ) }\end{array}$ & 327.7 & 487.9 \\
\hline $\begin{array}{l}\text { MPR of OROS-MPH treatment } \\
(\%, \text { mean } \pm \text { SD) }\end{array}$ & 73.4 & 30.9 \\
\hline ATX prescription $(n, \%)$ & 92 & 1.7 \\
\hline $\begin{array}{l}\text { Duration of ATX treatment (days, } \\
\text { mean } \pm \text { SD) }\end{array}$ & 161.4 & 221.6 \\
\hline MPR of ATX treatment $(\%$, mean \pm SD) & 85.3 & 22.6 \\
\hline
\end{tabular}

Note: Data are expressed as $n(\%)$ or mean \pm SD.

Abbreviations: IR-MPH, immediate-release methylphenidate; OROS-MPH, osmotic release oral system-methylphenidate; ATX, atomoxetine; MPR, medication possession ratio; ADHD, attention-deficit/hyperactivity disorder; SD, standard deviation.

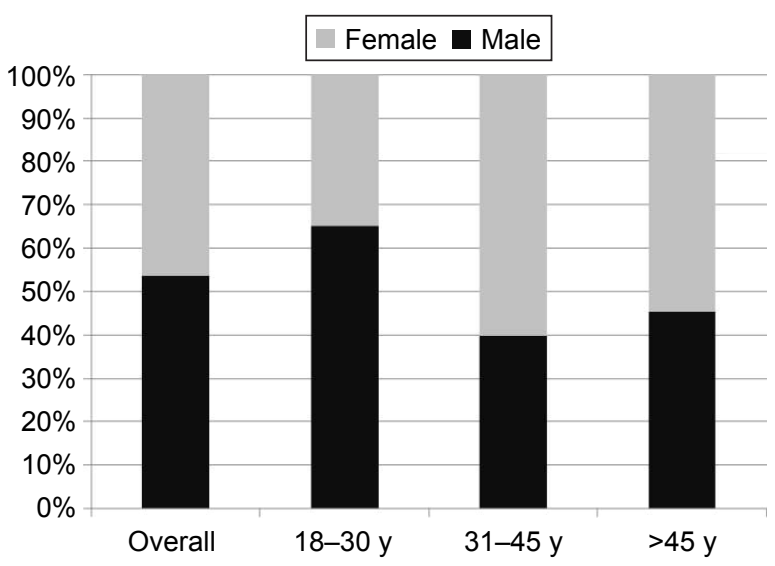

Figure I Sex distribution among three age groups in adult ADHD patients in Taiwan. Abbreviations: ADHD, attention-deficit/hyperactivity disorder; $y$, years. $\square>365$ days $\square$ 181-365 days $\square$ 31-180 days $\square \leq 30$ days

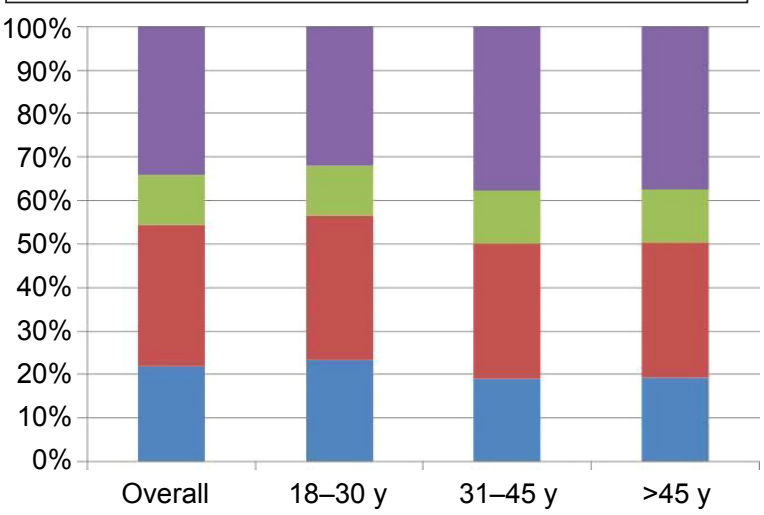

Figure 2 Different durations of medication treatment among three age groups in adult ADHD patients in Taiwan.

Abbreviations: ADHD, attention-deficit/hyperactivity disorder; y, years.

specialists of physicians (ie, general practitioner, pediatrician, or psychiatrist) are allowed to diagnose and treat ADHD in Taiwan. Therefore, the accessibility of medical care could not explain the low diagnosis rate of adult ADHD in Taiwan. In sum, it is suggested that there is still a large number of adults who meet the criteria for ADHD but do not seek medical care.

There are several possible explanations for the low diagnosis rate of adult ADHD in Taiwan. First, because the hyperactive/impulsive symptoms commonly reduce in adulthood, diagnosing ADHD in adults is more difficult than in children or adolescents. ${ }^{41}$ Second, cultural influences, medical resources, discretion of the physicians, and the

Table 3 Logistic regression model for factors associated with pharmacotherapy for adult ADHD

\begin{tabular}{|c|c|c|c|}
\hline Characteristics & n/N (\%) & aOR $(95 \% \mathrm{Cl})$ & $P$-value \\
\hline \multicolumn{4}{|l|}{ Age at diagnosis } \\
\hline 18-30 years (n, \%) & $1,919 / 2,822(68.0)$ & 1 & \\
\hline $31-45$ years $(n, \%)$ & $844 / 1,992(42.4)$ & $0.40(0.35-0.46)$ & $<0.001$ \\
\hline$>45$ years $(n, \%)$ & $224 / 583(38.4)$ & $0.30(0.26-0.36)$ & $<0.001$ \\
\hline \multicolumn{4}{|l|}{ Sex } \\
\hline Female & I, I42/2,502 (45.6) & I & \\
\hline Male & I,845/2,895 (63.7) & $1.79(1.59-2.02)$ & $<0.001$ \\
\hline \multicolumn{4}{|l|}{ ADHD subtypes } \\
\hline Inattentive type & $2,124 / 4,042(52.5)$ & I & \\
\hline $\mathrm{H} / \mathrm{I}$ or combined type & $863 / 1,355(63.7)$ & $1.23(|.07-1.4|)$ & 0.004 \\
\hline \multicolumn{4}{|c|}{ Psychiatric comorbidity } \\
\hline Tic disorders & $49 / 76(64.5)$ & $0.94(0.57-1.57)$ & 0.821 \\
\hline Intellectual disability & $182 / 396(46.0)$ & $0.54(0.44-0.68)$ & $<0.001$ \\
\hline Anxiety disorders & $2,2|7 / 3,54|(62.6)$ & $1.64(1.42-1.89)$ & $<0.001$ \\
\hline Depressive disorders & $75 \mathrm{I} / \mathrm{I}, 073(70.0)$ & $1.74(1.52-1.99)$ & $<0.001$ \\
\hline \multicolumn{4}{|c|}{ Hospital level } \\
\hline Hospitals & $2,048 / 3,983(5 \mathrm{I} .4)$ & 1 & \\
\hline Local medical clinics & $939 / 1,4 \mid 4(66.4)$ & I.55 (I.35-I.78) & $<0.001$ \\
\hline
\end{tabular}

Abbreviations: aOR, adjusted odds ratio; $95 \% \mathrm{Cl}, 95 \%$ confidence interval; $A D H D$, attention-deficit/hyperactivity disorder; $\mathrm{H} / \mathrm{l}$, hyperactive/impulsive. 
patients' willingness to receive treatment may influence the diagnosis rates of adult ADHD. ${ }^{5}$ Third, without referral from teachers or parents, self-recognizing attention-related problems is the main source of clinical referral in adults. However, adults often have better coping strategies to deal with ADHD symptoms than children, and are therefore less likely to seek medical help. Although the diagnosis rate of adult ADHD is low in Taiwan, it was found that the incidence rates of adult ADHD increased 10 times from 2000 ( 0.41 per 100,000 people) to 2011 (4.45 per 100,000 people). Besides, the annual proportion of the three age groups (18-30, $31-45$, and $>45$ years) did not significantly change during 2000-2011. This may indicate increased awareness of adult ADHD symptoms in clinicians and the general population throughout all age groups.

The results of this study were similar to a previous study which also used NHIRD in Taiwan from 2000-2005 for ADHD diagnosis. ${ }^{22}$ However, the present study included patients with at least two claims records of ADHD diagnosis from 2000 to 2011, but Huang et $\mathrm{al}^{22}$ included patients with only one claim record. This study therefore demonstrated a more reliable ADHD diagnosis rate and data more recently. Besides, Huang et $\mathrm{al}^{22}$ did not provide information about the types of treatment received by those patients. Nevertheless, similar to the finding of this study, they ${ }^{22}$ found very low health-seeking prevalence rate of ADHD in adult groups, higher diagnosis rate in younger age groups, and an increase in the trend of diagnosis in adult ADHD in Taiwan.

\section{Characteristics of adult ADHD}

A more equal male to female ratio (1.16) was found in adults with ADHD than in children with ADHD, and the adults with ADHD predominantly had the inattention subtype ADHD. These findings are compatible with previous studies. ${ }^{6,9,17,42}$ In concordance with the present study (Figure 1), a previous study that used NHIRD data in Taiwan also found that the ADHD diagnosis rate was female dominant among those older than $30 .{ }^{22}$ In childhood ADHD, it has been well established that boys have a higher prevalence rate than girls with a ratio ranging from $2: 1$ to $9: 1{ }^{43,44}$ In contrast to girls, boys are more likely to exhibit hyperactivity/impulse symptoms and have a higher probability of clinical referral and diagnosis of ADHD. In addition, the symptoms of ADHD, and particularly hyperactive/impulsive symptoms, naturally decrease at puberty or in early adulthood. ${ }^{39}$ Therefore, adults with ADHD, and especially women with ADHD, may be more likely to exhibit attention problems. In addition, adult women are more likely to seek psychiatric help than men, ${ }^{44,45}$ and therefore, women with manifestations of ADHD may be more likely to be diagnosed with ADHD than men. Taken together, these reasons may be associated with the sex distribution and predominance of the inattentive subtype in adult ADHD.

It was also found that adult ADHD was frequently comorbid with other psychiatric disorders including anxiety (65.6\%), depressive (49.5\%) and tic (1.4\%) disorders, and intellectual disabilities (7.3\%). Previous studies have also reported that as many as $47 \%-53 \%$ of adults with ADHD have comorbid anxiety disorders. ${ }^{24}$ In addition to anxiety disorders, depressive disorders have also been reported to be highly prevalent in adults with ADHD (11.5\%-53\%). 2,7,9,24 Because the symptoms of ADHD usually begin in childhood, the cumulative effects of these symptoms may lead some young adults with ADHD to eventually develop anxiety or depression. ${ }^{46,47}$ Substance abuse has also been a commonly reported comorbid disorder in previous studies. ${ }^{5,8}$ However, treatment for substance abuse is not covered by the NHI in Taiwan, and thus substance use disorders could not be analyzed in this study. The comorbid rates of tic disorders (1.4\%) and intellectual disabilities (7.3\%) were reported in adults with $\mathrm{ADHD}$, and an increasing number of studies have indicated that ADHD can increase the risk of developing numerous neuropsychiatric disorders. ${ }^{28,48,49}$ Taken together with the study findings, it is suggested that common psychiatric comorbidities of ADHD should be taken into consideration when managing such patients.

\section{Pharmacotherapy of adult ADHD}

In this study, about $55 \%$ of the adults diagnosed with ADHD received medications for ADHD. This result is quite similar to a study in the US which reported that $48 \%-58 \%$ of adults with ADHD received ADHD medications. ${ }^{17}$ On the contrary, unlike the data in USA which reported a steady increase in pharmacological treatment over time, ${ }^{17}$ the proportion of patients who received medication treatment in this study did not significantly change over time. Medication prescriptions may be associated with patients' acceptance, physicians' willingness, or even some other source. This indicates that the acceptance of medication treatment in public might not necessarily be elevated over time, to accompany an increased diagnosis rate of adult ADHD. Among the ADHD medications, IR-MPH was the most common medication prescribed by clinicians in Taiwan. The Bureau of NHI lists IR-MPH as the first choice of medication for adult ADHD, and OROS-MPH and ATX are only suggested for patients who experience poor drug compliance or are intolerant to the adverse effects of IR-MPH. 
In this study, the average duration of treatment was about 478.3 days, and a mean MPR of $69.3 \%$, an indicator of the intensity of pharmacological treatment, was found in the study population. ADHD is thought to be a life-long condition, ${ }^{5,50,51}$ however, adults with ADHD may develop adequate coping strategies and then be able to stop using medications. ${ }^{52}$ However, the reasons for discontinuing ADHD medication may also be related to other factors such as the severity of symptoms, adverse effects, treatment effectiveness, patients'/clinicians' attitude toward the medication, and social stigma,${ }^{8}$ all of which are difficult to analyze from claims data. Instead, factors associated with the use of ADHD medication were analyzed in the Taiwanese adult population. It was found that older age and having comorbid intellectual disabilities were associated with a lower probability of being prescribed with ADHD medications. Young adults may face tasks that require better attention or self-management skills such as attending university and finding a new job, whereas older adults may have developed strategies to compensate for the symptoms of ADHD, and are therefore less likely to receive pharmacotherapy. Interestingly, the youngest patients (18-30 years) had the shortest duration of treatment in the study population (Figure 2). It warrants further investigation on whether drug adherence was influenced by sociodemographic characteristics other than age (ie, sex or socioeconomic status).

Moreover, lower expectations of general performance in adults with intellectual disabilities may lead to less active treatment. However, having comorbid anxiety or depressive disorders increased the probability of being prescribed with medications. Several studies have suggested that adults with ADHD are at an increased risk of having depressive and anxiety disorders, ${ }^{6,18,52-54}$ and clinicians may feel more obliged to treat ADHD in these patients to lower the psychosocial stress resulting from the symptoms of ADHD.

\section{Limitations}

There are several limitations to this study. First, the diagnoses of adult ADHD were identified on the basis of ICD-9-CM codes only, and they were not validated using face-to-face diagnostic instruments. Therefore, the results represent the diagnosis rates of adult $\mathrm{ADHD}$, but not the actual prevalence of adult ADHD in Taiwan. Second, some clinical data such as the severity of ADHD symptoms, family history, past history, physical comorbidities, and treatment effects were not analyzed in this study. Third, because treatment of substance use disorders is not included in the NHIRD, the effect of substance abuse could not be analyzed. Fourth, the indications of drug prescriptions were difficult to ascertain through data collection, and it was simply assumed that all medicines were used for ADHD. Fifth, information on non-pharmacological treatment was not analyzed for ADHD in this study. Finally, the study did not analyze how many adults had more than one course of ADHD medication treatment.

\section{Conclusion}

This population-based study showed an increasing trend in the diagnosis rate of adult ADHD; however, this rate is still low compared with Western countries. Adult patients with ADHD seeking medical care are characterized by a similar male to female ratio, inattentive type of ADHD, and frequent psychiatric comorbidities. Approximately 55\% of the adult patients with ADHD received medication for their ADHD. Overall, the findings in this study suggest that continuous efforts are needed to increase public awareness about adult ADHD.

\section{Acknowledgments}

The authors thank Mr Keng-Hao Chang and Mr Yao-cheng Lyu for retrieving data from the NHIRD-TW. This study was sponsored by the Chang Gung Memorial Hospital Research Projects (CMRPG8D0581, CMRPG2D0421, CMRPG2B0113, CLRPG2D0381). The study is based in part on data from the NHIRD-TW provided by the NHI Administration, Ministry of Health and Welfare and managed by the National Health Research Institutes (registration number: NHIRD-102-088). The interpretations and conclusions contained herein do not represent those of the NHI Administration, Ministry of Health and Welfare or National Health Research Institutes.

\section{Disclosure}

The authors report no conflicts of interest in this work.

\section{References}

1. Nijmeijer JS, Minderaa RB, Buitelaar JK, Mulligan A, Hartman CA, Hoekstra PJ. Attention-deficit/hyperactivity disorder and social dysfunctioning. Clin Psychol Rev. 2008;28(4):692-708.

2. Kooij SJ, Bejerot S, Blackwell A, et al. European consensus statement on diagnosis and treatment of adult ADHD: The European Network Adult ADHD. BMC Psychiatry. 2010;10:67.

3. Mannuzza S, Klein RG, Bessler A, Malloy P, LaPadula M. Adult outcome of hyperactive boys. Educational achievement, occupational rank, and psychiatric status. Arch Gen Psychiatry. 1993;50(7):565-576.

4. Faraone SV, Biederman J, Mick E. The age-dependent decline of attention deficit hyperactivity disorder: a meta-analysis of follow-up studies. Psychol Med. 2006;36(2):159-165.

5. Ramos-Quiroga JA, Montoya A, Kutzelnigg A, Deberdt W, Sobanski E. Attention deficit hyperactivity disorder in the European adult population: prevalence, disease awareness, and treatment guidelines. Curr Med Res Opin. 2013;29(9):1093-1104. 
6. Moffitt TE, Houts R, Asherson P, et al. Is adult ADHD a childhoodonset neurodevelopmental disorder? Evidence from a four-decade longitudinal cohort study. Am J Psychiatry. 2015;172(10):967-977.

7. Sobanski E, Bruggemann D, Alm B, et al. Psychiatric comorbidity and functional impairment in a clinically referred sample of adults with attention-deficit/hyperactivity disorder (ADHD). Eur Arch Psychiatry Clin Neurosci. 2007;257(7):371-377.

8. Kooij JJ, Huss M, Asherson P, et al. Distinguishing comorbidity and successful management of adult ADHD. J Atten Disord. 2012; 16(5 Suppl):3S-19S.

9. de Zwaan M, Gruss B, Muller A, et al. The estimated prevalence and correlates of adult ADHD in a German community sample. Eur Arch Psychiatry Clin Neurosci. 2012;262(1):79-86.

10. Biederman J, Wilens T, Mick E, Milberger S, Spencer TJ, Faraone SV. Psychoactive substance use disorders in adults with attention deficit hyperactivity disorder (ADHD): effects of ADHD and psychiatric comorbidity. Am J Psychiatry. 1995;152(11):1652-1658.

11. Arias AJ, Gelernter J, Chan G, et al. Correlates of co-occurring ADHD in drug-dependent subjects: prevalence and features of substance dependence and psychiatric disorders. Addict Behav. 2008;33(9):1199-1207.

12. A 14-month randomized clinical trial of treatment strategies for attention-deficit/hyperactivity disorder. The MTA Cooperative Group. Multimodal Treatment Study of Children with ADHD. Arch Gen Psychiatry. 1999;56(12):1073-1086.

13. Storebo OJ, Ramstad E, Krogh HB, et al. Methylphenidate for children and adolescents with attention deficit hyperactivity disorder (ADHD). Cochrane Database Syst Rev. 2015;11:CD009885.

14. Krause J, Krause KH, Dresel SH, la Fougere C, Ackenheil M. ADHD in adolescence and adulthood, with a special focus on the dopamine transporter and nicotine. Dialogues Clin Neurosci. 2006;8(1):29-36.

15. Wigal T, Brams M, Gasior M, et al. Randomized, double-blind, placebocontrolled, crossover study of the efficacy and safety of lisdexamfetamine dimesylate in adults with attention-deficit/hyperactivity disorder: novel findings using a simulated adult workplace environment design. Behav Brain Funct. 2010;6:34.

16. Torgersen T, Gjervan B, Rasmussen K. Treatment of adult ADHD: is current knowledge useful to clinicians? Neuropsychiatr Dis Treat. 2008; 4(1):177-186.

17. Knight TK, Kawatkar A, Hodgkins $P$, et al. Prevalence and incidence of adult attention deficit/hyperactivity disorder in a large managed care population. Curr Med Res Opin. 2014;30(7):1291-1299.

18. Montejano L, Sasane R, Hodgkins P, Russo L, Huse D. Adult ADHD: prevalence of diagnosis in a US population with employer health insurance. Curr Med Res Opin. 2011;27 (Suppl 2):5-11.

19. Aragones E, Lluis Pinol J, Ramos-Quiroga JA, Lopez-Cortacans G, Caballero A, Bosch R. Prevalencia del déficit de atención e hiperactividad en personas adultas según el registro de las historias clínicas informatizadas de atención primaria [Prevalence in adults of attention deficit hyperactivity disorder using the medical records of primary care]. Rev Esp Salud Publica. 2010;84(4):417-422. Spanish.

20. Schlander M, Schwarz O, Trott GE, Viapiano M, Bonauer N. Who cares for patients with attention-deficit/hyperactivity disorder (ADHD)? Insights from Nordbaden (Germany) on administrative prevalence and physician involvement in health care provision. Eur Child Adolesc Psychiatry. 2007;16(7):430-438.

21. Fayyad J, De Graaf R, Kessler R, et al. Cross-national prevalence and correlates of adult attention-deficit hyperactivity disorder. $\mathrm{Br} J$ Psychiatry. 2007;190:402-409.

22. Huang CL, Chu CC, Cheng TJ, Weng SF. Epidemiology of treated attention-deficit/hyperactivity disorder (ADHD) across the lifespan in Taiwan: a nationwide population-based longitudinal study. PLoS One. 2014;9(4):e95014

23. Simon V, Czobor P, Balint S, Meszaros A, Bitter I. Prevalence and correlates of adult attention-deficit hyperactivity disorder: meta-analysis. Br J Psychiatry. 2009;194(3):204-211.
24. Kessler RC, Adler L, Barkley R, et al. The prevalence and correlates of adult ADHD in the United States: results from the National Comorbidity Survey Replication. Am J Psychiatry. 2006;163(4):716-723.

25. Franke B, Faraone SV, Asherson P, et al. The genetics of attention deficit/hyperactivity disorder in adults, a review. Mol Psychiatry. 2012; 17(10):960-987.

26. Kessler RC, Adler LA, Barkley R, et al. Patterns and predictors of attention-deficit/hyperactivity disorder persistence into adulthood: results from the national comorbidity survey replication. Biol Psychiatry. 2005;57(11):1442-1451.

27. Asherson P, Chen W, Craddock B, Taylor E. Adult attention-deficit hyperactivity disorder: recognition and treatment in general adult psychiatry. Br J Psychiatry. 2007;190:4-5.

28. Pinkhardt EH, Kassubek J, Brummer D, et al. Intensified testing for attention-deficit hyperactivity disorder (ADHD) in girls should reduce depression and smoking in adult females and the prevalence of ADHD in the longterm. Med Hypotheses. 2009;72(4):409-412.

29. Stuhec M, Locatelli I, Svab V. Trends in attention-deficit/hyperactivity disorder drug consumption in children and adolescents in Slovenia from 2001 to 2012: a drug use study from a national perspective. J Child Adolesc Psychopharmacol. 2015;25(3):254-259.

30. McCarthy S, Asherson P, Coghill D, et al. Attention-deficit hyperactivity disorder: treatment discontinuation in adolescents and young adults. Br J Psychiatry. 2009;194(3):273-277.

31. Wu CS, Lai MS, Gau SS, Wang SC, Tsai HJ. Concordance between patient self-reports and claims data on clinical diagnoses, medication use, and health system utilization in Taiwan. PLoS One. 2014;9(12): e112257.

32. Gajria K, Lu M, Sikirica V, et al. Adherence, persistence, and medication discontinuation in patients with attention-deficit/hyperactivity disorder - a systematic literature review. Neuropsychiatr Dis Treat. 2014; 10:1543-1569.

33. Lachaine J, Beauchemin C, Sasane R, Hodgkins PS. Treatment patterns, adherence, and persistence in ADHD: a Canadian perspective. Postgrad Med. 2012;124(3):139-148.

34. Directorate-General of Budget Accounting and Statistics, Executive Yuan, Taiwan, 2015. Resident Population by 5-Year, 10-Year Age Group. Available from http://sowf.moi.gov.tw/stat/month/m1-06.ods. Accessed October 29, 2015

35. Polanczyk G, de Lima MS, Horta BL, Biederman J, Rohde LA. The worldwide prevalence of ADHD: a systematic review and metaregression analysis. Am J Psychiatry. 2007;164(6):942-948.

36. Thomas R, Sanders S, Doust J, Beller E, Glasziou P. Prevalence of attention-deficit/hyperactivity disorder: a systematic review and metaanalysis. Pediatrics. 2015;135(4):e994-e1001.

37. Gau SS, Chong MY, Chen TH, Cheng AT. A 3-year panel study of mental disorders among adolescents in Taiwan. Am J Psychiatry. 2005; 162(7):1344-1350.

38. Wang YC, Chong MY, Chou WJ, Yang JL. Prevalence of attention deficit hyperactivity disorder in primary school children in Taiwan. J Formos Med Assoc. 1993;92(2):133-138.

39. Cherkasova M, Sulla EM, Dalena KL, Ponde MP, Hechtman L. Developmental course of attention deficit hyperactivity disorder and its predictors. J Can Acad Child Adolesc Psychiatry. 2013;22(1):47-54.

40. McCarthy S, Wilton L, Murray ML, Hodgkins P, Asherson P, Wong IC. The epidemiology of pharmacologically treated attention deficit hyperactivity disorder (ADHD) in children, adolescents and adults in UK primary care. BMC Pediatr. 2012;12:78.

41. Jerome L. Adult attention-deficit hyperactivity disorder is hard to diagnose and is undertreated. Can J Psychiatry. 2016;61(1):59.

42. Caci HM, Morin AJ, Tran A. Prevalence and correlates of attention deficit hyperactivity disorder in adults from a French community sample. J Nerv Ment Dis. 2014;202(4):324-332.

43. Gershon J. A meta-analytic review of gender differences in ADHD. J Atten Disord. 2002;5(3):143-154. 
44. Gaub M, Carlson CL. Gender differences in ADHD: a meta-analysis and critical review. J Am Acad Child Adolesc Psychiatry. 1997;36(8): 1036-1045.

45. Wicks-Nelson R, Israel A. Behaviour Disorders of Childhood. 3rd ed. Upper Saddle River, NJ: Prentice-Hall; 1997.

46. Daviss WB. A review of co-morbid depression in pediatric ADHD: etiology, phenomenology, and treatment. J Child Adolesc Psychopharmacol. 2008;18(6):565-571.

47. Daviss WB, Diler R. Does comorbid depression predict subsequent adverse life events in youth with attention-deficit/hyperactivity disorders? J Child Adolesc Psychopharmacol. 2012;22(1):65-71.

48. Huss M, Poustka F, Lehmkuhl G, Lehmkuhl U. No increase in long-term risk for nicotine use disorders after treatment with methylphenidate in children with attention-deficit/hyperactivity disorder (ADHD): evidence from a non-randomised retrospective study. J Neural Transm. 2008; 115(2):335-339.

49. Halmoy A, Fasmer OB, Gillberg C, Haavik J. Occupational outcome in adult ADHD: impact of symptom profile, comorbid psychiatric problems, and treatment: a cross-sectional study of 414 clinically diagnosed adult ADHD patients. J Atten Disord. 2009;13(2):175-187.
50. Ghanizadeh A, Mohammadi MR, Akhondzadeh S, Sanaei-Zadeh H. Attention deficit hyperactivity disorder in imprisoned individuals a review. Psychiatr Danub. 2011;23(2):139-144.

51. Mattingly G, Culpepper L, Babcock T, Arnold V. Aiming for remission in adults with attention-deficit/hyperactivity disorder: the primary care goal. Postgrad Med. 2015;127(3):323-329.

52. Volkow ND, Swanson JM. Clinical practice: adult attention deficithyperactivity disorder. N Engl J Med. 2013;369(20):1935-1944.

53. Shaw M, Hodgkins $\mathrm{P}$, Caci $\mathrm{H}$, et al. A systematic review and analysis of long-term outcomes in attention deficit hyperactivity disorder: effects of treatment and non-treatment. BMC Med. 2012;10:99.

54. Goksoyr PK, Nottestad JA. The burden of untreated ADHD among adults: the role of stimulant medication. Addict Behav. 2008;33(2): $342-346$.
Neuropsychiatric Disease and Treatment

\section{Publish your work in this journal}

Neuropsychiatric Disease and Treatment is an international, peerreviewed journal of clinical therapeutics and pharmacology focusing on concise rapid reporting of clinical or pre-clinical studies on a range of neuropsychiatric and neurological disorders. This journal is indexed on PubMed Central, the 'PsycINFO' database and CAS,

\section{Dovepress}

and is the official journal of The International Neuropsychiatric Association (INA). The manuscript management system is completely online and includes a very quick and fair peer-review system, which is all easy to use. Visit http://www.dovepress.com/testimonials.php to read real quotes from published authors.

Submit your manuscript here: http://www.dovepress.com/neuropsychiatric-disease-and-treatment-journal 